\title{
PERANCANGAN DAN IMPLEMENTASI SISTEM INFORMASI PENGELOLAAN MESJID HABIB HAMID BIN ABBAS ALBAHASYIM BERBASIS WEB
}

\author{
Insanul Fikri ${ }^{1, a^{*}}$, Gita Ayu Syafarina ${ }^{2, b}$, Rusdina $^{3, c}$ \\ ${ }^{1} \mathrm{JI}$ Sutoyo S Komp Rajawali No 69 Banjarmasin, \\ 2 Jl. Mahligai, \\ 3 JI. A. Yani Simp. Ulin \\ a ihsan.fti@gmail.com, b gitaayusyafarina@gmail.com , crussidina@gmail.com
}

\begin{abstract}
Abstrak
Mesjis Habib Hamid bin Abbas albahasyim adalah salah satu Mesjid yang ramai dikunjungi karena berdekatan dengan wisata religius Kubah Habib Hamid Albahasyim yang setiap hari nya selalu padat pengunjung baik dalam maupun dari luar kota. Selama ini pengelolaan keuangan, jadwal-jadwal tausyiah, kotak amal mesjid ini masih dicatat di buku besar catatan mesjid, dan hanya di masukkan ke Excel untuk laporan Bulanan, sehingga sering kali jika ada kegiatan yang berkaitan dengan mesjid tidak terdata dengan baik oleh pengelola. Dari hal diatas, sesuai dengan perkembangan teknologi yang sudah sangat maju maka kami merancang sistem informasi pengelolaan mesjid berbasis web untuk memudahkan pengurus mesjid mengelola berbagai kegiatan dan keuangan mesjid
\end{abstract}

Kata kunci : Pengelolaan Mesjid, Sistem Informasi, WEB

\begin{abstract}
The Habib Hamid bin Abbas Albahasyim Mosque is one of the most visited mosques because it is close to the Habib Hamid Albahasyim Dome religious tourism which is always crowded with visitors both inside and outside the city. So far, financial management, tausyiah schedules, mosque charity boxes are still recorded in the mosque's ledger, and only entered into Excel for monthly reports, so that often activities related to the mosque are not properly recorded by the manager. From the above, in accordance with technological developments that have been very advanced, we designed a web-based mosque management information system to make it easier for mosque administrators to manage various mosque activities and finances.
\end{abstract}

Keywords : Mosque Management, Information System, WEB 


\section{PENDAHULUAN}

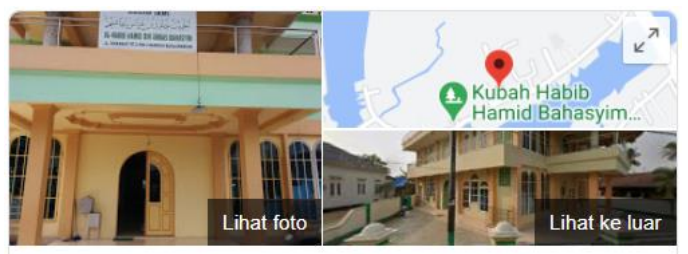

Masjid Jami Al - Habib Hamid Bin Abbas Bahasyim

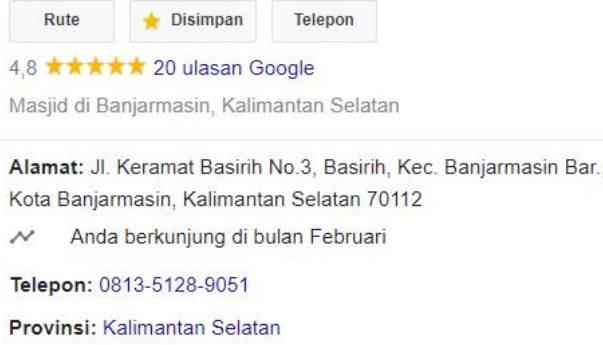

Gambar 1 Mesjid Habib Hamid Sumber : Google Maps

Mesjid Habib Hamid Bin Abbas al Bahasyim adalah salah satu mesjid besar yang berada Kelurahan basirih Kubah , Banjarmasin barat Kota Banjarmasin. Mesjid ini berdekatan dengan Wisata Religius Kubah Habib Hamid Al Basahyim dan Kubah Habib Abu Bakar Bin Salim Al Habsyi yang sering dikunjungi penjiarah dari berbagai kota, yang tidak hanya dari provinsi Kalimantan Selatan saja, tapi juga Provinsi lain seperti saerah jawa dan sumatera bahkan ada yang dari luar negri seperti Hadra Maut dan Turki.

Dalam pengelolaan kegiatan Mesjid, Pengurus hanya mencatat secara manual pada buku besar mesjid. Baru di ketik di Excel untuk laporan bulanan mesjid. Kegiatan seperti jadwal imam harian, Imam Jumat dan khatib, catatan kas mesjid seperti infaq masuk dan keluar, dan lainnya seharusnya sudah bisa di lakukan dengan mudah pada perangkat seperti laptop pengurus. Dengan adanya sebuah sistem informasi berbasis web, tentunya akan memudahkan pengurus mesjid nanti nya dalam penyimpanan data serta pengelolaan kas mesjid.

\section{METODE PENELITIAN}

Metode Penelitian yang dipergunakan adalah metode pengembangan sistem yaitu menggunakan proses SDLC (System Development Life Cyle) ,pengembangan atau rekayasa sistem informasi (softwareengineering) dengan model Waterfall. .

Jalan proses model Waterfall yaitu :

a. Tahap awal, yaitu adalah tahap perencanaan (planning), adalah menyangkut studi studi tentang kebutuhan pengguna (user's specification), studi-studi kelayakan (feasibility study) baik secara teknik maupun secara teknologi serta penjadwalan suatu proyek sistem informasi atau perangkat lunak.

b. Tahap kedua, yaitu tahap analisis sistem yang akan dibuat, yang dimana kita berusaha mengidentifikasi berbagai permasalahan yang muncul dan merancang sistem yang akan dibuat.

c. Tahap ketiga, adalah tahap design yaitu dimana mencoba mencari solusi dari permasalahan yang didapat dari tahap analisis.

d. Tahap keempat, yaitu tahap mengimplementasikan perencanaan sistem ke situasi nyata atau melakukan pengkodean/coding.

e. Tahap kelima, yaitu tahap pengujian yang mana tujuannya untuk menentukan apakah sistem atau perangkat lunak yang dibuat sudah sesuai dengan kebutuhan pengguna dan untuk menghilangkan atau meminimalisasi cacat program (defect) sehingga sistem yang dikembangkan benar-benar akan membantu para pengguna saat mereka melakukan aktivitas-aktivitasnya.

f. Tahap keenam atau tahap terakhir yaitu tahap perawatan sistem yang digunakan, dimana pada tahap ini mulai dimulainya proses pengoperasian sistem dan jika diperlukan melakukan perbaikan-perbaikan kecil untuk lebih memudahkan pengguna 
Perancangan sistem merupakan kegiatan pengembangan prosedur dan proses yang berjalan untuk menghasilkan suatu yang baru atau memperbaiki sistem yang ada untuk meningkatkan efektifitas kerja. Perancangan model sistem yang diusulkan dari Aplikasi ini . akan dituangkan dalam bentuk Unified Modeling Language (UML).

Unified Modeling Language (UML) menurut (Fowler, 2005) adalah keluarga notasi grafis yang didukung oleh metamodel tunggal, yang membantu pendeskripsian dan desain sistem perangkat lunak, khususnya sistem yang dibangun menggunakan pemrograman berorientasi objek. UML muncul karena adanya kebutuhan pemodelan visual untuk menspesifikasikan, menggambarkan, membangun, dan dokumentasi dari sistem perangkat lunak.

Berikut adalah bentuk Class Diagram yang dibuat untuk Pengelolaan Manajemen Dan Kegiatan Masjid Berbasis Web

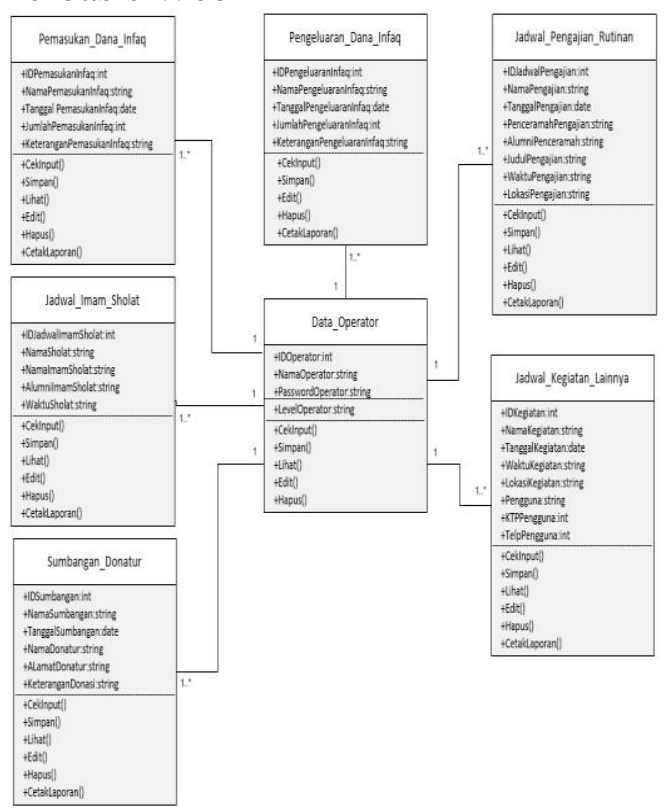

Gambar 2 : Class Diagram Aplikasi

Sumber : Pribadi

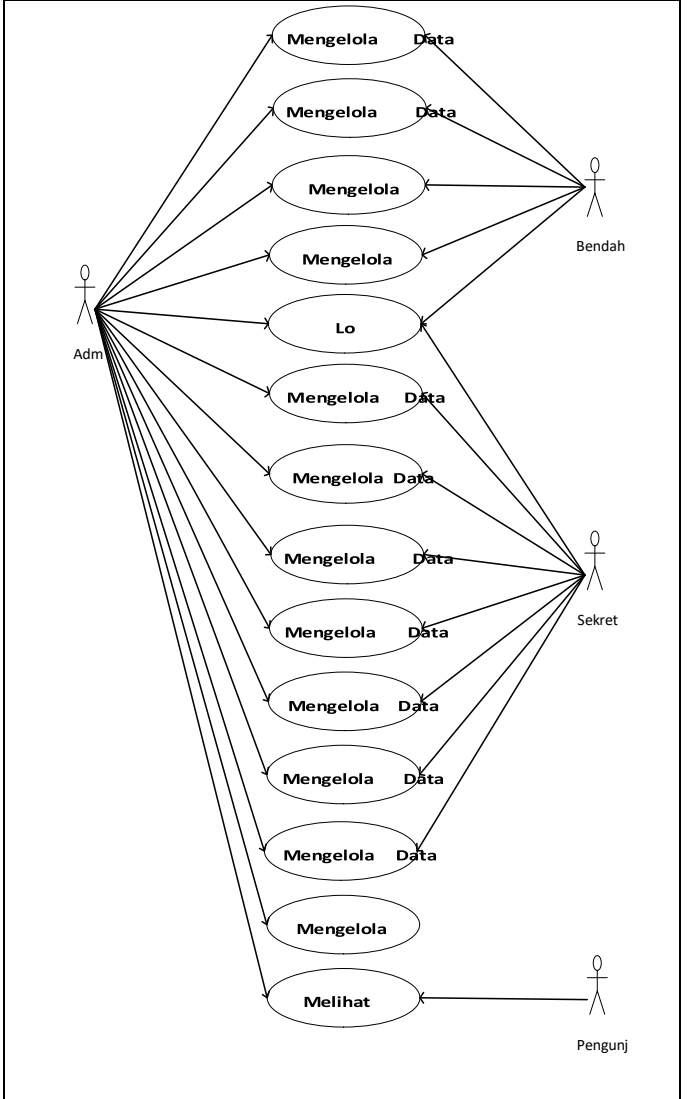

Gambar 3 : Usecase Diagram Aplikasi

Sumber : Pribadi

Form aplikasi yang buat mengikuti kebutuhan sistem yang diperlukan dalam pengelolaan atau manajemen Mesjid yaitu :

1. Form Login

2. Form Menu Utama Admin

3. Form Input Pemasukan Dana Infaq

4. Form Input Operator

5. Form Input Pengeluaran Dana Infaq

6. Form Menu Utama Sekretaris

7. Form Input Bilal Dan Khatib

8. Form Input Imam Sholat

9. Form Input Pengajian Rutinan

10.Form Input Kegiatan

11.Form Input Data Kuliah Subuh

12.Form Menu Utama Bendahara

Sedangkan Output atau luaran sistem yang di rancang adalah seperti dibawah ini :

1. Laporan Pemasukkan Infaq Mingguan 
2. Laporan Dana Infaq Perbulan

3. Dana Infaq Pertahun

4. Laporan Pengeluaran Dana Setiap Bulan

5. Donator Zakat

6. Laporan Donator Qurban

7. Jadwal Kegiatan Jum'atan

8. Laporan Jadwal Pengajian

9. Laporan Kuliah Subuh

10.Tausiyah Dzuhur

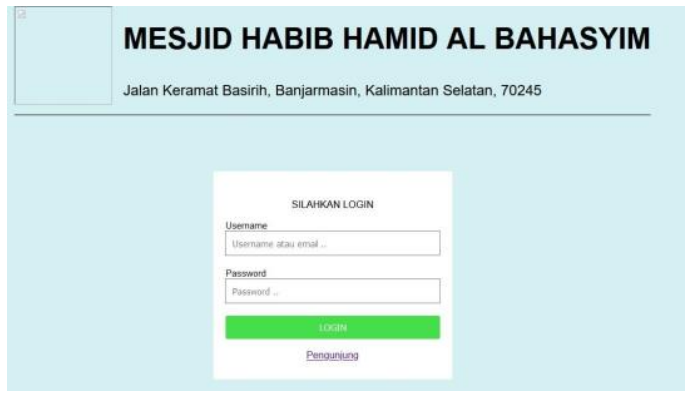

Gambar 4 :Tampilan Form login Sumber : Pribadi

Input Pemasukan Dana Infaq

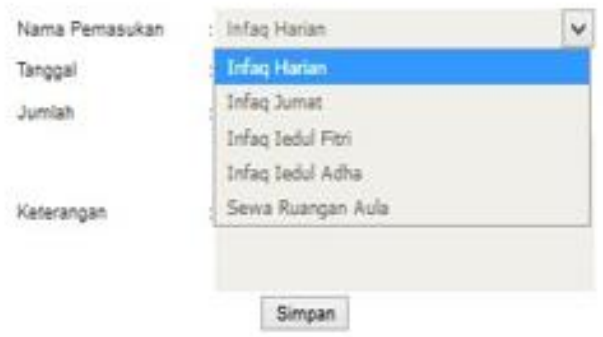

Input Pengeluaran Dana Infaq

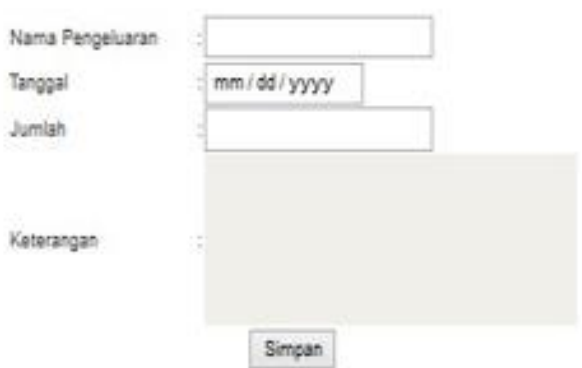

Gambar 5 : Input Dana masuk dan Keluar Infaq Mesjid Sumber : Pribadi

\section{Input Data Operator}

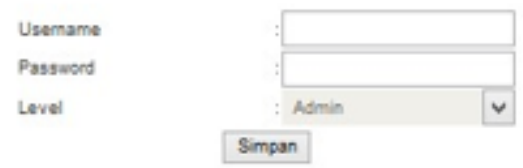

Input Donatur Zakat

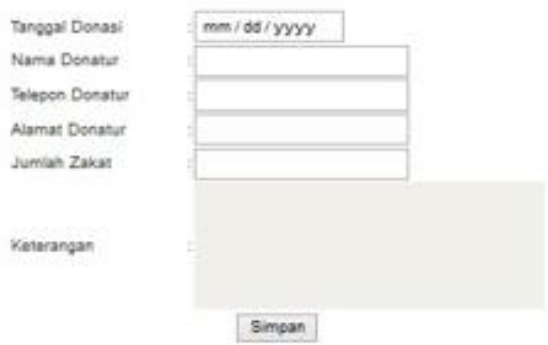

Gambar 6 : Form Data Operator dan Donatur Zakat

Sumber : Pribadi

\section{Input Jadwal Bilal dan Khatib}

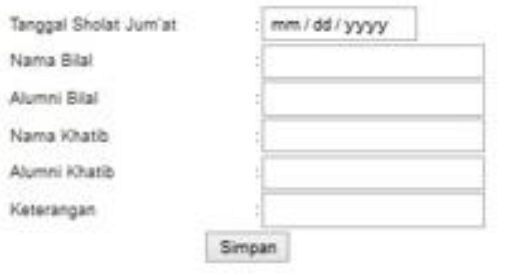

\section{Input Jadwal Imam Sholat}

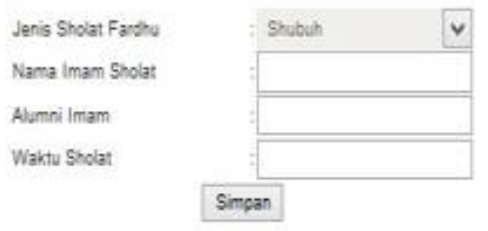

Gambar 7 : Jadwal Bilal, khatib dan Imam Sumber : Pribadi Input Jadwal Pengajian Rutinan

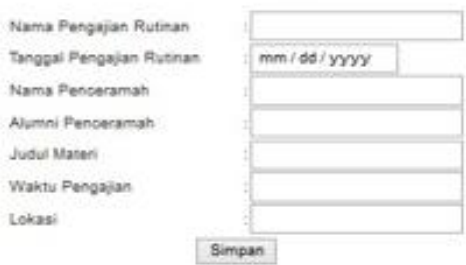




\section{Lihat Laporan Semua Dana Infaq}

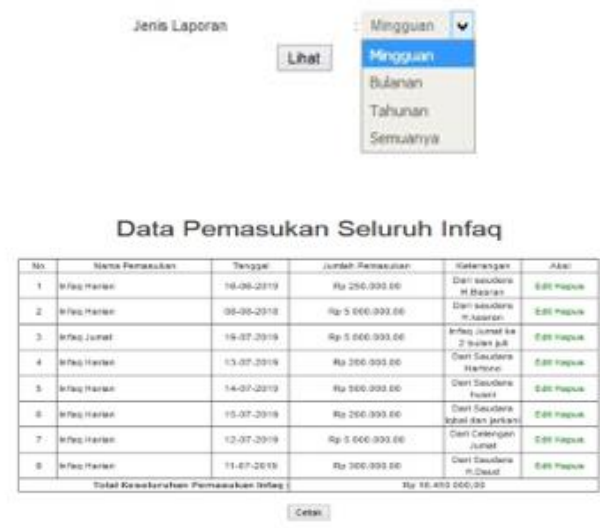

Gambar 8 : Form Jadwal Pengajian dan laporan Dana Infaq Sumber : Pribadi

\section{HASIL DAN PEMBAHASAN}

Pengujian yang dilakukan untuk sistem yang sudah selesai adalah pengujian BlackBox. Pengujian black box berfokus pada persyaratan fungsional perangkat lunak tanpa menguji desain dan program.

Berikut adalah tabel Pengujian Blackbox :

Tabel 1 Pengujian Black Box

\begin{tabular}{|c|c|c|}
\hline Item Uji & Detail Pengujian & $\begin{array}{c}\text { Jenis } \\
\text { Pengujian }\end{array}$ \\
\hline Pengolahan Data Operator & $\begin{array}{l}\text { New (input data } \\
\text { baru) Insert } \\
\text { (tambah/simpan) } \\
\text { Update (edit) } \\
\text { Delete (hapus) }\end{array}$ & Black Box \\
\hline Pengolahan Data Infaq & $\begin{array}{l}\text { New (input data } \\
\text { baru) Insert } \\
\text { (tambah/simpan) } \\
\text { Update (edit) } \\
\text { Delete (hapus) } \\
\text { Print (cetak) }\end{array}$ & Black Box \\
\hline Pengolahan Data Zakat & $\begin{array}{l}\text { New (input data } \\
\text { baru) Insert } \\
\text { (tambah/simpan) } \\
\text { Update (edit) } \\
\text { Delete (hapus) } \\
\text { Print (cetak) }\end{array}$ & Black Box \\
\hline Pengolahan Data Qurban & $\begin{array}{l}\text { New (input data } \\
\text { baru) Insert } \\
\text { (tambah/simpan) } \\
\text { Update (edit) } \\
\text { Delete (hapus) } \\
\text { Print (cetak) }\end{array}$ & Black Box \\
\hline $\begin{array}{l}\text { Pengolahan Data Bilal } \\
\text { Khatib } \\
\text { Dan Imam Jum'at }\end{array}$ & $\begin{array}{l}\text { New (input data } \\
\text { baru) Insert } \\
\text { (tambah/simpan) } \\
\text { Update (edit) }\end{array}$ & Black Box \\
\hline
\end{tabular}

\begin{tabular}{|l|l|l|}
\hline & $\begin{array}{l}\text { Delete (hapus) } \\
\text { Print (cetak) }\end{array}$ & \\
\hline $\begin{array}{l}\text { Pengolahan Data Imam } \\
\text { Sholat }\end{array}$ & $\begin{array}{l}\text { New (input data } \\
\text { baru) Insert } \\
\text { (tambah/simpan) } \\
\text { Update (edit) } \\
\text { Delete (hapus) }\end{array}$ & Black Box \\
\hline $\begin{array}{l}\text { Pengolahan Data Pengajian } \\
\text { Rutinan }\end{array}$ & $\begin{array}{l}\text { Print (cetak) } \\
\text { baru) Insert } \\
\text { (tambah/simpan) } \\
\text { Update (edit) }\end{array}$ & Black Box \\
& $\begin{array}{l}\text { Delete (hapus) } \\
\text { Print (cetak) }\end{array}$ & \\
\hline $\begin{array}{l}\text { Pengolahan Data Kegiatan } \\
\text { Lainnya }\end{array}$ & $\begin{array}{l}\text { New (input data } \\
\text { baru) Insert } \\
\text { (tambah/simpan) } \\
\text { Update (edit) } \\
\text { Delete (hapus) } \\
\text { Print (cetak) }\end{array}$ & Box \\
\hline
\end{tabular}

\section{KESIMPULAN}

Sebuah Sistem otomatis dengan menggunakan Pemrograman PHP dengan data base MySQL sangat Memudahkan pengelolaan / manjemen Mesjid Habib Hamid Bin Abbas Albahasyim . Data-data yang dimasuskkan ke Database bisa tersimpan dengan baik dan lebih mudah di cari dengan adanya sistem terkomputerisasi.

\section{REFERENSI}

[1] Arief, M. R. (2011). Pemrograman Web Dinamis menggunakan PHP dan MySQL. In M. R. Arief, Pemrograman Web Dinamis menggunakan PHP dan MySQL. Yogyakarta: Andi Offset.

[2] Fowler, M. (2005). In M. Fowler, UML Distilled 3th Ed. Panduan Singkat Bahasa Pemodelan Objek Standar. Yogyakarta: Andi Offset.

[3] Jurnal Tabligh. (2016). Studi Pengelolaan Masjid Agung AlAzhar Jakarta, 84-96.

[4] Kadir, A. (2013). Pengertian MySQL. In A. Kadir, Buku Pintar Programer Pemula PHP. Yogyakarta: Mediakom.

[5] Rina Alfah, T. V. R., 2018. Sistem 
E-Prescribing Dan BARCODE SYSTEM Untuk Resep Obat Di Rumah Sakit. Jurnal Teknologi Informasi Universitas Lambung Mangkurat (JTIULM), 03(Vol. 3 No. 2 (2018)), pp. 59-70.

[6] Rusdina, 2018. Perancangan Aplikasi Rawat Inap Di Klinik Bidan Sumirat, Pengaron Kalimantan Selatan. Balikpapan, Seminar Nasional Teknologi Informasi, Komunikasi Dan Administrasi (Seminastika) Universitas Mulia Balikpapan 